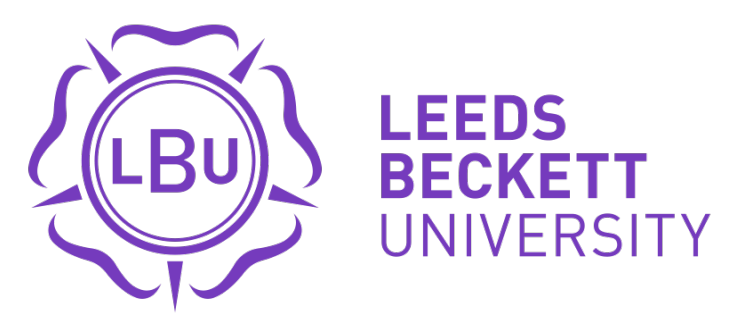

Citation:

Maher, AJ and Williams, D and Sparkes, AC (2020) Teaching non-normative bodies : simulating visual impairments as embodied pedagogy in action. Sport, Education and Society, 25 (5). pp. 530-542. ISSN 1357-3322 DOI: https://doi.org/10.1080/13573322.2019.1617127

Link to Leeds Beckett Repository record:

https://eprints.leedsbeckett.ac.uk/id/eprint/5967/

Document Version:

Article (Accepted Version)

This is an Accepted Manuscript of an article published by Taylor \& Francis in Sport, Education and Society on 13 May 2019, available online: http://www.tandfonline.com/10.1080/13573322.2019.1617127

The aim of the Leeds Beckett Repository is to provide open access to our research, as required by funder policies and permitted by publishers and copyright law.

The Leeds Beckett repository holds a wide range of publications, each of which has been checked for copyright and the relevant embargo period has been applied by the Research Services team.

We operate on a standard take-down policy. If you are the author or publisher of an output and you would like it removed from the repository, please contact us and we will investigate on a case-by-case basis.

Each thesis in the repository has been cleared where necessary by the author for third party copyright. If you would like a thesis to be removed from the repository or believe there is an issue with copyright, please contact us on openaccess@leedsbeckett.ac.uk and we will investigate on a case-by-case basis. 


\section{Author Details}

Corresponding author: Anthony J. Maher, Pedagogy, Professional Development and Politics in Physical Education and Sport Research Group, Edge Hill University, Ormskirk, UK. Mahera@edgehill.ac.uk.

Dean Williams, Pedagogy, Professional Development and Politics in Physical Education and Sport Research Group, Edge Hill University, Ormskirk, UK.

Andrew C. Sparkes, Institute for Sport, Physical Activity and Leisure, Leeds Beckett University, Leeds, UK. 


\title{
Teaching non-normative bodies: Simulating visual impairments as embodied pedagogy in action
}

\begin{abstract}
In an attempt to better prepare prospective PE teachers for teaching pupils with disabilities, our research takes up the call of Sparkes et al. (2017) for an accumulation of "case studies involving teacher educators attempting to put embodied pedagogy into action" (p.10). We used snapshot vignettes to reflect on our experiences of delivering learning activities that endeavoured to enable 90 prospective PE teachers to (1) simulate visual impairment (VI); and (2) plan and deliver learning activities to peers who were simulating VI. Our discussion centres on the authenticity of simulations and the pedagogical development of prospective PE teachers. From our observations, we remain sceptical about the extent to which the nondisabled Self can empathise with the disabled Other through embodied simulation because of the ease at which the Self could and would step out of the shoes of the Other by removing blindfolds. This disrupted attempts to blur the lines between the prospective PE teachers' Self and the disabled Other, and thus the extent to which knowledge of the disabled Other in PE was embodied. We did observe, however, some positive pedagogical developments during simulations. These included increased: clarity and precision of verbal instructions; use of pedagogical touch; knowledge of how to adapt learning activities; and critical thought about the concept of educational inclusion. To finish, we argue that the simulation of VI appears to impact positively of the inclusive pedagogies of our prospective teachers, but we call for future research that explores the ethics of these simulations.
\end{abstract}

\section{Key words}

Disability; visual impairment; simulation; embodied pedagogy; teacher education.

\section{Introduction}

Physical education (PE) teachers are said to lack the knowledge, skills, experience and confidence to provide suitably challenging learning experiences for pupils with disabilities (Vickerman and Maher, 2019). One purported way of addressing this is to focus more on disability and inclusion issues during the initial teacher education (ITE) and continued professional development (CPD) of pre- and in-service PE teachers (Vickerman and Coates, 
2009). More specifically, calls have been made to provide and support opportunities for preservice teachers to cover the principles and practice of inclusive PE through, for instance, using a social and relational model lens to explore 'disability', and consider the ideological and practical basis of different concepts of 'educational inclusion'. This approach is said to be important for improving teacher attitudes towards teaching children with and without disabilities together in the same space, increasing teacher awareness of the needs and capabilities of children with different 'types' of disabilities, and exploring strategies for teaching and assessing the learning of children with disabilities (Vickerman and Maher, 2019). In this respect, hands-on experience with children with disabilities is said to be key for developing positive attitudes towards inclusion and teaching pupils with disabilities (Coates, 2012). Maher et al. (2017) are among a growing number of academics who have championed the use of special school-based placements for gaining this experience. However, it can be difficult to arrange special school based-placements because (1) so few are in close proximity to universities; (2) it can be problematic quality-assuring the 'PE' offered; and (3) some are already saturated with pre-service teachers. Moreover, as Maher et al., (2017) found, some pre-service PE teachers are not adequately prepared for working in what can be the very challenging, albeit rewarding, learning environments of special schools, especially for those with limited previous exposure to children with disabilities.

In an attempt to better prepare those who aspire to become PE teachers for special schoolbased placements, and ultimately all those who teach pupils with disabilities, our research aims to take up the call of Sparkes et al. (2017) for an accumulation of "case studies involving teacher educators attempting to put embodied pedagogy into action" in order to "help us to better understand additional ways in which this form of pedagogy can contribute to ensuring that prospective teachers have the knowledge, skills, experience and ideological 
commitment to develop a more inclusive culture in school PE" (p.10). In this respect, our case study centres on the (dis)abled body, embodied pedagogy and simulation, each of which will now be explored in turn.

\section{The (dis)abled body and embodied pedagogy}

The body has historically been either ignored or marginalised as a source of knowledge by educational academics and practitioners (Macintyre-Latta and Buck, 2008). Learning is often thought to be an entirely cognitive process. Scholars and practitioners of corporeal practices such as PE, dance, art, theatre and music, however, have contributed towards increasing the legitimacy of focusing on embodied knowledge as part of wider discussions about teaching, learning and assessment (e.g. Bowman, 2004; Dixon and Senior, 2011; Forgasz and McDonough, 2017; Munro, 2018). In PE, this is encapsulated in a focus on 'learning through the physical'. Little attention has been paid, though, to non-normative bodies. The bodies of children with disabilities, including those with visual impairments (VI), like all children, are situated within fluid and changing contexts and situations (Munro, 2018). The experiences that children with VI have in PE, and the meanings they construct of, and through, experiences, are therefore perceived through their bodies. In this respect, there is a growing body of research, within the United States (US) mainly, that has asked adults with VI about their school experiences of PE. Key findings highlight perceptions of exclusionary practices in PE, particularly in relation to a lack of support from teachers, and incidents of peer-led isolation and bullying (Haegele and Zhu, 2017). When the focus turns to the embodiment of (in)ability in PE, teachers were thought to consider the bodies of children with VI as 'unable' and 'flawed' (Haegele and Kirk, 2018; Haegele et al., 2018). 
A child's learning in PE, particularly because of the subject's corporeal nature, is an active process anchored in, through, with, and because of the body (MacLachlan, 2004). Rather than subordinating non-normative bodies when developing teaching and learning strategies, we need to consider them as being central to our pedagogies and construction(s) of knowledge. This may go some way to redressing a situation which sees pupils with disabilities (Tant and Watelain, 2016), including those with VI (Haegele and Poretta, 2015), participating less frequently and in fewer physical activities than their age-peers, both during and once they leave compulsory education. Embodied pedagogy can be a useful approach for facilitating such embodied learning experiences. In this regard, Dixon and Senior (2011) emphasise the importance of distinguishing between embodied forms of teaching, learning and pedagogy. They suggest that "embodied pedagogy includes embodied teaching and learning but is conceptualised through 'pedagogy as relational' - between teaching and learning and between teacher and learner" (p. 473). We would add that it also includes learner bodies in motion in relation to the moving bodies of other learners.

Instead of utilising an embodied pedagogy that would, as van Manen (1991) argues, be "cemented deep in the nature of the relationship between the Self and the Other" (p. 31), we wanted our prospective PE teachers to embody the (disabled) Other, if only superficially and ephemerally. This, we postulate, may enable them to empathetically imagine what it is like to live in, with and through a non-normative body, thus bridging, or at least narrowing, the gap between propositional and practical knowledge about teaching children with disabilities in PE. Here, we hoped to extend the work of Sparkes et al. (2017) who used simulation as a way of attempting to embody a physical disability among prospective PE teachers, by instead focusing on a sensory disability. 


\section{Simulating disability as embodied pedagogy}

Like Carrington et al. (2011), we wanted to use simulation so that our prospective teachers could apply their theoretical knowledge through repeated trail, whilst they learn and develop their craft. This will allow them to experiment with different (inclusive) teaching strategies without it having an adverse effect on the learning of children with disabilities. In an educational context, technology has been used to simulate disability, both through virtual reality (Pivik et al., 2002) and online software programmes (Salend, 2005). These simulations require participants to cognitively imagine themselves in the shoes of the Other. The extent to which visual stimuli and cognitive imaginings alone can enable people to embody disability is open to discussion. For our part, we posit that a more body-active approach may be required in order to, as Blakeslee and Blakeslee (2007) suggest, "stimulate the visceral and internal tissues of the body" (p. 213). That way, our prospective teachers may be able to connect the mind-body and, thus, experience PE in, with and through disabled bodies. Hence, for this research we reflect on our experiences of facilitating learning activities that attempted to enable prospective teachers to (1) simulate VI; and (2) plan and deliver learning activities to peers who were simulating VI.

\section{Theoretical Framework}

\section{Philosophical position}

An interpretivist ontology guided the research in that we, the researchers, were committed to making sense of how simulating a VI was experienced by prospective teachers of PE. Here, we embraced the notion that there are multiple realities (Maxwell, 2012) that are socially 
constructed, dynamic and continuously influx. Therefore, even though the prospective PE teachers were studying the same degree course, at the same university, had similar career aspirations, and experienced comparable simulated activities at the same time in a shared temporal space, the sense they made of and meaning given to those experiences may differ because each individual has their own - sometimes compatible, other times not - ideologies, values, intentions and lived experiences, all of which can shape experiential interpretation and meaning construction. Similarly, we, as researchers, have our own ideologies and experiences that will inevitably spill into the research process (Creswell and Poth, 2018). Thus, given that we used observations and group discussions to generate data, it is important to note that each of us is committed, in our professional capacities, to ensuring that prospective PE teachers (1) are fully exposed to the realities of working with children with disabilities, and (2) have the commensurate skills, knowledge and experiences to allow them to support the learning of those children.

\section{Methodology}

\section{University module and participant recruitment}

The prospective PE teachers were selected from a level six, final-year elective module, delivered at a university in the north of England, UK. The module was entitled: Special educational needs and disability (SEND) in physical education and school sport, and was offered as part of a three-year BA (Hons.) Physical Education and School Sport degree. Anthony and Dean constructed the module. We delivered lectures, seminars and practical activities in an attempt to better prepare students for a career as inclusive educators. Whilst some learning undoubtedly occurred because of all the experiences we facilitated during the module, it is the practical activities that are the focus of our article. Anthony and Dean 
constructed the practical activities in order to provide opportunities for prospective PE teachers to (1) experience simulating physical and sensory disabilities; and (2) gain experience teaching peers who were simulating such disabilities. Again, it must be acknowledged that learning occurred in different ways and for differing reasons across all practical activities but, because of word constraints, the simulation of VI will be at the centre of this article. The specifics of these activities come through the vignettes offered later in Phase One and Phase Two.

A total of 90 prospective PE teachers participated in the research. The participants: (1) were prospective (i.e. intended to apply to train to become a teacher once their undergraduate studies were complete) PE teachers; and (2) had attended (some or all of) the six, two-hour practical activities. The participants were taught in four separate groups of up to 23 people, depending on attendance. Groups were mostly random but effort was made to achieve an even gender split, which was mostly indicative of the gender ratio of the degree programme and module. The research gained ethical approval from Anthony and Dean's university, and was informed by BERA's (2018) ethical guidelines. Anthony used part of the first lecture to distribute an information letter explaining the aim and purpose of the research to all students studying the SEND in PE module, and to ask for their involvement. He was then on hand to answer questions to ensure that consent was fully informed (Bryman, 2015). Whilst it was carefully explained that they did not have to participate, and that it would not adversely affect their studies, all students agreed to be involved in the research. Students were also told, from the outset, that they could withdraw from the research for any or no reason by informing Anthony via email. 


\section{Methods}

The practical activities were observed, and group discussions initiated and facilitated, as a way of generating data. While most of the data generated and represented related to what we saw rather than heard, group discussions were crucial for helping us, as teachers and researchers, to make sense of how activities were experienced by prospective PE teachers, from their own perspective. Inevitably, this influenced the ways we implemented activities. Field diaries were kept by Anthony and Dean to ensure that there was a record of what had been seen and heard. Observations were unstructured in that we did not ascribe to validated criteria relating to the incidents, events or conversations that should be recorded. Instead, we were mindful of the research objectives and, on that basis, recorded what we deemed salient. Given our philosophical position, our ideologies, values, knowledge and professional and personal experiences formed the prism through which we made sense of the behaviours of the prospective PE teachers as they experienced simulating VI. Given that we, the researchers, facilitated the simulated activities, we had already become, according to Bryman (2015), immersed in the field. In this respect, it is crucial to acknowledge our role as, what Atkinson (2012) terms, teacher-researcher-observer. Here, we acted as teachers in that we structured the learning environment and developed and facilitated many of the learning activities. Crucially, though, we did not experience the PE activities whilst simulating VI with the prospective teachers, although we have done on previous occasions. The lines here between observer-as-participant and participant-as-observer overlapped and were blurred. In short, we were not a part of the group under investigation but we were actively involved in influencing their behaviours and shaping their experiences. Accordingly, we sought to engage in the culturally responsive relational reflexive ethics described by Lahman et al. (2011). This required us to value the interplay between researchers and participants, requiring that the former be sensitive to the interactions between self, others and situations, to notice the 
reactions to a research situation and then adapt in a responsive, ethical, and moral way that recognises power imbalances and social differences between the teacher-researcher-observer and the prospective PE teachers.

\section{Data analysis}

In an attempt to make sense of and give meaning to the data generated from observations and group discussions, Anthony, who performed the initial analysis, operated as what Denzin and Lincoln (2011) termed an analytical bricoleur. Specifically, the diaries of Anthony and Dean were analysed thematically (Braun et al., 2016), and also reflexively considered in relation to immersed experiences as teacher-researcher-observer of prospective teachers simulating VI during PE lessons. The aim here was to construct patterns of similarity and coherence in the data. Once these initial themes had been generated, they were sent to Dean to scrutinise. Given that we, the researchers, have differing lived experiences, academic knowledge and observe the social world through different theoretical lenses (Smith and McGannon, 2017), the aim here was not to increase the reliability of thematic analysis. Instead, Dean, and later Andrew, acted as critical friends which enabled Anthony to reflect on the decisions made during that thematic analysis. Indeed, the intention was to encourage reflexivity by challenging Anthony's construction of knowledge (Smith and McGannon, 2017). Subsequently, the constructed themes were used by Anthony to develop the vignettes presented below, and to give structure to the discussion offered thereafter.

\section{Snapshot Vignettes}

Phase One (14th October 2017) 
Before the first session, we (Anthony and Dean) trawled through the activity resources we had collected over the years to get some ideas. We agreed that students would first experience simulating VI through the use of blindfolds, and that multiple learning activities would be delivered to develop among students a sense of how PE may be experienced differently by children with VI depending on the space, rules of the activities, equipment, and bodily movements required. We felt that all students should gain experience simulating VI, and that they should participate in the learning activities with others who are not simulating VI. This, we hoped, would replicate an 'inclusive' PE lesson in that the bodies of people with and without VI would be interacting in the same temporal space.

For the first activity, students wore blindfolds and very slowly and carefully moved through space. This was aimed at helping them to 'feel' what it is like to move through space, changing direction, at different speeds, with a VI. At first, students were very apprehensive in that their movements were extremely slow, rigid, tense and tight. The loss of vision impacted significantly on the fluidity of their movements. In an attempt to decrease trepidation, we organised students into pairs, and asked one person to wear the blindfold and the other to act as an assistant, guiding them through space. Importantly, we did not give additional instructions because we wanted students to develop their own support strategies. Interestingly, the movements quickly became more fluid and dynamic. At that point, we encouraged students to increase the pace at which their bodies were moving through space. The purpose here was for them to experience fast, health-improving movement, from the perspective of a child with a VI so they could 'feel' rapid movement. 
It was interesting to observe the ways in which the students endeavoured to fulfil the role of assistant. Some used verbal instructions to guide and direct students' movement patterns. However, many of those simulating VI did not like this approach because they found it difficult to follow the instructions, sometimes because they were not clear or detailed enough, other times because they preferred the comfort and safety of the assistant using touch as a way of ensuring that the did not collide with other students. At this point, there were multiple bodies moving through space in different directions and at different speeds. It was the unpredictability of the movement patterns that most concerned students. The pairs experimented with different ways of using touch as a pedagogical tool to guide those simulating VI. Examples of techniques included: one hand on elbow; one hand on shoulder (standing to the side); one hand on each shoulder (standing behind); and holding one hand (standing to the side and in front). Interestingly, some of the students raised concerns about an adult holding the hand of a child in order to guide them. As a remedy, one student suggested that a piece of fabric could be held by both child and assistant to prevent direct touch.

After these experiences, we gathered students together and asked them to explain how they felt during the simulated activities. Terms such as 'scared', 'vulnerable', 'uncertain', and 'useless' were mentioned. These emotions were drawn on to explain why students, without exception, removed blindfolds during simulations. A few also suggested that they would 'hate to be blind'. A discussion then developed, among the students, about how difficult the lives of people with VI must be, particularly in relation to everyday tasks such as 'taking showers', 'getting dressed', 'brushing teeth' and 'cooking food'. Whilst much of the language used here was informed by a deficit understanding of disability, it appeared that 
students were beginning to appreciation the connection between what we were doing in the session and the everyday lives and embodied experiences of children with VI.

The next learning activity was aligned to the 'modification' element of Black and Stevenson's (2011) inclusion spectrum. For this, we wanted students to remove blindfolds and to perform a pass in netball (chest, bounce and overhead) statically and then in motion. Then, we introduced a defender so that students would have to consider strategy, select an appropriate pass, and use verbal and non-verbal forms of communication. Once these basic activities had been performed, we split students into groups of three and gave one member a blindfold and encouraged them to discuss how the inclusion spectrum could be used to modify the activity for children with a VI. We wanted them to make a connection between the simulation they had recently experienced and an appropriately inclusive pedagogical strategy for children with VI. Initially, students found it difficult to adjust to include the person simulating a VI. In particular, they struggled to consider how the space, task, equipment and/or role of participants could be modified so that the student simulating the VI could have an appropriately challenging and meaningful experience. Interestingly, and perhaps unknowingly, many of the students using the blindfold would remove it when discussing and trialling the proposed adaptations. Therefore, we brought the group together to unpick the pedagogical challenges associating with developing an inclusive learning activity.

Students said that they would have to drastically reconsider their traditional approaches to performing and teaching passing drills if they were to include the person simulating the VI. Eventually, the discussion moved on to how other senses could be roused in order to compensate for the loss of sight. A ball containing a bell was suggested as one possible 
option so that the students' hearing could be utilised. Through practicing the drill, students quickly realised that overhead and chest passes were inappropriate because the noise made by the bell was minimal; it was not enough of a cue for the student simulating the VI to have the time to process the speed, trajectory and direction of travel of the ball so that they could adjust their bodies accordingly. Instead, the bounce pass was deemed the most appropriate because the ball making contact with the floor made the bell ring loudest. Students also experimented with the space between the giver and receiver as a way of determining the optimal distance; optimal in that it gave the receiver enough time to react to noise of the bell when the ball connected with the floor so that they could successfully receive it.

Gradually, it was obvious that students began to appreciate the necessity of giving detailed verbal guidance and feedback relating to where their bodies were in relation to other bodies, the success (or not) of the pass they received, and what the receiver should expect from the pass. Additionally, students began to experiment with the pitch and tone of their voice to indicate their position on the playing field. They also shook the ball to ring the bell because that alerted the other players to the position of the ball-carrier. This was useful for teammates using the blindfold because it meant that they could turn their bodies to face the ball-carrier in order to receive a pass. However, it also made the defender aware of the intentions of the attackers. Soon, students realised that non-verbal cues such as pointing into space to indicate their direction of travel and where they wanted to receive the ball were now redundant as a form of communication between themselves and those simulating VI.

During a class discussion, some students mentioned that teaching assistants could help support these type of activities in schools. In particular, touch was mentioned again as a 
pedagogical tool to help position and facilitate the movement of a child with a VI. Some examples, which came from the students, included: touch the person on the left or right shoulder to indicate the direction of travel of the ball. Multiple touches could be used to facilitate speed of delivery or distance from the body that the ball was travelling. Students suggested that this would also be useful when working with pupils with hearing and/or visual impairments. This was the first time that anyone had mentioned the wider applicability of the pedagogical strategies.

Phase Two (31st October 2017)

The first activity was based on the concerns expressed by students last week that modifications may have a negative impact on the learning of other pupils. For this, we focused on the parallel dimension of the inclusion spectrum (Black and Stevenson, 2011). Here, we asked students to use a serve in badminton as it would traditionally be taught and then to develop two 'regressed' versions so that, essentially, there would be three parallel versions of the serve. Regressed versions included the use of short-hand rackets so that the hand was closer to the striking area; rackets with larger surface areas; and changing the shuttlecock for balls of varying sizes and colours. Students also used hoops of different sizes and colours as targets, which were placed at varying distances. Interestingly, one group used beanbags placed on rackets for those who found it difficult to make contact between a moving shuttlecock/ball and racket head. In these instances, it appeared that students had transferred what they had learned earlier to a different activity in that they seemed to have become much more aware of how learning tasks could be changed and different equipment utilised. During a group discussion, students suggested that parallel learning such as this was an inclusive form of PE. It was suggested that 'ability grouping' happens often in PE as well 
as other subjects. Students did suggest, however, that pupils should share the same learning space and that there should be transfer between groupings when possible. This approach, according to them, reinforces the idea that the level and type of support required by a pupil with VI would depend on what was being taught, how it was being taught, and in what context, something we had previously discussed during a lecture. Interestingly, this was the first time students had verbalised a connection between the conceptual aspects taught during lectures and what we experienced during practical activities.

Next, we introduced glasses that simulate different types of VI in order to challenge the perception that VI relates entirely to blindness. Instead, we wanted students to appreciate that VI can manifest in many different ways, pose different challenges, and create additional opportunities for teachers and pupils in PE. The activity also aimed to allow students to experience teaching their peers, all of whom were simulating different visual impairments. This, we hoped, would allow the students to experience the challenges associated with teaching children with VI, so that they could develop appropriate pedagogical solutions. To begin, we created two groups of eight people. Half the students wore VI glasses and half blindfolds. The expectation was that VI glasses would be rotated so that all students experienced wearing them. Like the previous week, students were asked to begin by moving through space, changing direction, at a speed they found comfortable. Again, guides were assigned to prevent accidents and, after a time, roles were swapped. From our observations if appeared that the movements of student had become, in a relatively short time, much more fluid and certain. There definitely seemed to be less apprehension than the first time blindfolds were used. Some students, again, lifted blindfolds either when talking to their guide or as a safety value when their fear of the unknown increased. Similarly, we observed some of those wearing the glasses looking either under or over the rim of the glasses, 
especially when they were moving at a fast pace. We tried to police this activity by reminding the students of the importance of this being as close to an 'authentic' experience as possible.

For the next learning activity, two students were asked to teach the other six members of their group for five minutes. We gave the students information cards relating to versions of goalball, to stimulate ideas. We mentioned the importance of progressions and asked the first pair to begin with a basic learning activity relating to goalball e.g. a drill focusing on shooting accuracy. The intention was for each pair to work towards the full version of goalball, which would be delivered by the final pair. The progressions were important from a pedagogical perspective as a way of ensuring that all students were suitably challenged, but also in relation to health and safety given that students were still trying to get a sense of their nonnormative bodies moving in relation to other bodies through space. Initially, the students found it extremely challenging teaching those simulating VI. Often, the student teachers demonstrated activities, which was obviously a poor pedagogical approach given that those simulating VI could not see their demonstrations. Similarly, student teachers often used inappropriate verbal instructions, which those simulating VI found difficult to enact. For example, student teachers would say: 'stand in a line', or, 'sit in a circle'. Here, students simulating a VI found it challenging to perform these instructions because of the difficulty they experienced trying to position their bodies in relation to the moving bodies of others. Very quickly, student teachers identified this issue and used touch as a pedagogical tool to move bodies into desired formations. Interestingly, when it came to the next pair of student teachers, they seemed to learn from these experiences when it was their turn to teach. The detail of their verbal instruction was much more appropriate, and they more readily used touch as a pedagogical tool. Other sounds were also created as cues. For example, students clapped their hands and shook the ball which contained a bell so that those simulating VI had 
a clearer sense of the positions of other bodies, including the teachers' bodies. This became particularly important when bodies where moving through space at difference levels and in different directions.

At the end of the teaching episodes, we brought the group together for a discussion. Here, the student teachers expressed the initial difficulty they experienced trying explain tasks to students simulating VI. They mentioned the fact that they, almost intuitive, started by demonstrating tasks but quickly realised that this approach was inappropriate. They also explained that they had realised that the hand gestures they used, such as pointing in a particular direction, were also redundant. Students suggested that they take these approaches for granted and did not appreciate the implications for children with VI. All suggested that they found it a very challenging learning experience despite the fact that they were teaching, what they considered, very basic and simplistic skills and activities. There was also mention of what was being learned through the activities. Students cast particular focus on the social domain of learning given that they had to rely more on each other and explore different, and sometimes newer ways, of interacting with each other. Further, students discussed how getting children without a VI to experience a simulation may contribute to the 'affective' development of those children through learning about difference, and developing inclusive values and empathy. The cognitive dimension of learning was also highlighted given that decisions had to be made, strategies developed and problems overcome. Interestingly, there was no mention of the physical domain of learning, which often dominates perceptions of the nature and purpose of PE.

\section{Reflective Discussion}




\section{Authenticity of simulations}

A number of significant issues were identified as we tried to make sense of the vignettes. First, we consider the 'authenticity' of the simulations. This ties into broader discussions about whether a person with a normative body can empathise, cognitively and/or affectively, with a person with a non-normative body. Here, cognitive empathy denotes a human's mental capacity to make attributions about the beliefs and intentions of the Other (Baron-Cohen et al., 2013). Thus, we are interested to understand whether simulation can be used as a vehicle for prospective teachers to 'know' (cognitively) what it is like to be and think like the disabled Other. According to Coplan (2011), this can be achieved through simulation whereby the prospective teachers attempt to mentally reconstruct the pupil's beliefs and experiences, while maintaining a clear sense of differentiation between the Self and the Other. The prospective teacher imagines they are the pupil, in the situation of the pupil, but acknowledges that they are not the pupil in that situation. This mental process is tied to ideas relating to embodied learning and embodied knowledge whereby prospective teachers try to cognitively transport themselves into the shoes of the disabled Other in order to know what it is like for the disabled Other. Affective empathy is about whether the PE teacher can feel what the pupil feels; that the teacher experiences the same emotions as the pupil in any given situation (Cooper, 2011). On both accounts, we have our reservations about whether the nondisabled Self can empathise with the disabled Other. From our observations it was apparent that those simulating VI could and would frequently remove the blindfold and, thus, step out of the shoes of the Other, typically when they experienced emotional discomfort. We did try and discourage blindfold removal but, from an ethical standpoint, it was important that students had this option if they experienced distress. At times, students appeared to remove the blindfolds unconsciously. Nonetheless, the wider point is that students could remove the blindfold, whereas VIs obviously cannot be removed. Inevitable, this disrupted attempts to 
blur the lines between the prospective teachers' Self and the disabled Other, and thus the extent to which knowledge of the disabled Other in PE was embodied. For us, questions remain about the relationship between the duration of the simulation, its authenticity, and the development of empathy. In total, students experienced four hours of practical activities relating to simulating VIs. Unfortunately, we did not time how long students actually spent wearing the blindfolds, but it was much less. What we do not know is if longer periods of simulating VI, in different contexts and situations, would increase empathy. Perhaps this is something for future research to consider.

Our scepticism of authenticity was reinforced as we reflected on some of the comments made by the students when describing their emotions while simulating VI. Terms such as 'scared', 'vulnerable', 'uncertain', and 'useless' were used. For some academics - and there is disagreement about how affective empathy is conceptualised - these comments are indicative of what Coplan (2011, p. 7) terms "reactive emotions". These emotions may not be sufficiently accurate representations of a pupil with VI's contextual-dependent and situated psychological state and, therefore, misrepresent the type of emotions experienced by the pupil with VI during the PE lessons. This is problematic because it may mean that the learning that occurs and knowledge that is embodied through these simulations may be inaccurate and misleading. While there is an ever-growing body of knowledge relating to the PE experiences of those with VI, this focuses on the value attributed to PE (Kurkova et al., 2015), activity preferences and modifications (Lieberman et al., 2006), and exclusionary experiences (Haegele and Zhu, 2017). Unfortunately, there is a notable lack of research that explores the perceptual-emotional experiences of children with VI about their bodies in motion in PE to offer a comparison. This is something for future research to address. More generally, it is concerning that the affective dimension of empathy is neglected by researchers because this 
form of empathy is said to be crucial for forming social bonds between people (Singer, 2006) such as teachers and pupils (with VI). The argument thus follows that PE teachers must be empathetic, both cognitively and affectively, if they are to develop a strong and productive relationship with their pupils. This is crucial when working with pupils with disabilities because, as Morley et al. (2005) suggested, teachers who are empathetic are more likely to have positive attitudes towards pupils with disabilities, and are more likely to be committed to including them in PE.

\section{Pedagogical development through simulations}

While we raise questions about the authenticity of the simulated experiences, it is important to note that the vignettes featured a number of potential benefits of simulation as a form of embodied pedagogy. For instance, it appeared to impact positively on student teachers' 'inclusive' pedagogies. In this respect, it was interesting to observe the ways in which student teachers experimented with different pedagogical approaches as they tried to get a sense of how best to facilitate the movements and, thus, learning of those simulating VI. Very quickly, there was a realisation that nonverbal forms of communication such as pointing and other hand gestures, which the student teachers initially used almost unconsciously, were now redundant. The clarity and precision of verbal instructions was something that also developed among prospective teachers because the person simulating the VI needed to develop a vivid picture in their minds of the position of their bodies in relation to other bodies and the space in which they found themselves. This became especially crucial when those bodies were moving through space. In this respect, Lieberman et al. (2014) argue the importance of PE teachers helping children with VI to explore key features of their environment, such as the 
layout and dimensions of playing areas, so that they can develop the orientation skills necessary to engaging in PE and social life more generally.

As part of prospective teachers' pedagogical experimentations, they trialled different approaches to using touch as a pedagogical tool, something which most had never engaged with before. This more tactile approach to physically supporting the movements of bodies through space is now used only sparingly in PE because of the prevalence of no touch discourses (Caldeborg et al., 2019) - except, perhaps, when the focus is on complex dance and gymnastic sequences. Nonetheless, it is an established technique for helping nonnormative bodies, especially those with VI, to feel how the body should move during more dynamic learning activities (Lieberman et al., 2012), such as throwing a discus. Such physical guidance, whereby teachers' bodies are engaged for pedagogical purposes, was used by our students, without prompt, as a substitute for demonstrations. This was well-received by the students simulating VI as they considered it a welcome support mechanism, especially when they became fearful that their moving bodies would crash into the walls or other moving bodies. Moreover, it is indicative of established approaches to embodied learning whereby the pedagogy becomes relational (Dixon and Senior, 2011) in that it connects the bodies of teacher and learners as a way of knowledge being embodied by both parties. That is to say, the student simulating the VI (learner) melding the mind-body by feeling what it is like to move their bodies in more fluid and dynamic ways, and the other student (teacher) stimulating the "visceral and internal tissues" (Blakeslee and Blakeslee, 2007, p. 213) of their own bodies to learn about using touch for pedagogical purposes. 
Another key benefit of the simulations is that they encouraged the prospective teachers to use the inclusion spectrum (Black and Stevenson, 2011) in creative ways, particularly vis-à-vis modifying learning activities to suit the needs and capabilities of both those simulating VI and those not. This is useful because it is tied to the concept of equity, rather than a one size fits all concept such as equality. Significantly, the hegemony of equal opportunities discourses in schools has disadvantaged some children with SEND - in PE especially because it is rooted in normative and medical model ways of thinking about education, which expects children with disabilities to 'fit in' to the cultural norms of schools that often do not cater for their needs (Maher, 2018). Prospective teachers also began to critique the concept of 'inclusion' by thinking in new ways (for them) about what inclusive PE entails. For example, through adapting activities, particularly team games, students started to consider whether these changes would have a negative impact on the learning and development of others in the group. It is important to note that this has been a key concern of PE teachers for a long time now (Morley et al., 2005). Nonetheless, the simulations allowed our students to consider this point from the embodied perspective of the teacher, pupil with VI, and pupil without VI, as they engaged with an embodied curriculum. Ultimately, for our students, when attempts to be inclusive were perceived to have a negative impact on the learning and development of others, their teaching could no longer be considered inclusive. This view is supported by Vickerman and Maher (2019) who claim that inclusive PE lessons should meet the needs and capitalise on the capabilities of all pupils, not just those with disabilities. While the perceptions of prospective PE teachers have been captured through our research, the data presented is mostly based on our reflections as teacher educators and researchers. Therefore, future research should gather thick descriptions (Sparkes and Smith, 2014) from prospective and, ideally, serving PE teachers, about their experiences of simulation in order to gain a more balanced and rounded view about its pedagogical possibilities. From a teacher educator 
standpoint, the next step is for participants to gain experience supporting the delivery of PE to children with VI to better understand the usefulness of the pedagogical learning that has taken place through simulations.

\section{The ethics of simulation}

To end, we acknowledge that the use of blindfolds does not capture the range and diversity of visual impairments, nor the lived and embodied experiences of people with VI. In the same vein, we are aware that our vignettes and discussion about VI are anchored in and through our lives as able-bodied people. Therefore, it is difficult to know how our (ableist) portrayals of VI would be understood by people with VI. Therefore, there is a need for future research to explore the uses of simulation from the perspective of people with VI. Despite these notable limitations, simulating VI served as a useful tool to develop teacher pedagogies. Blindfolds are cheap and easy to use. The same, perhaps, could be said about the use of ear defenders to simulate hearing impairments. Other impairments, however, are perhaps more difficult, if not impossible, to simulate; take, for example, intellectual disabilities (ID). To the best of our knowledge no equipment exists to support the simulation of ID. More importantly, though, there are also significant ethical issues associated with trying to embodied through, for instance, 'acting' an ID and/or cognitively 'imagining' an ID. Given the historical propensity for people without disabilities to speak and act for people with disabilities (Goodley, 2017), there are significant ethical issues associated with attempts to try and step into the shoes of the disabled Other. For instance, there was mention of the use of deficit model language by our prospective teachers when discussing the lives of people with VI. While this finding is not unique (see, also, Sparkes et al., 2019) we certainly want to avoid a situation where our students think and claim to know what it is like to live the life of the 
disabled Other. While we argue that the simulation of VI appears to impact positively of the inclusive pedagogies of our prospective teachers, we call for future research that explores what people with VI think about these simulations so that we can ensure that the simulations our students experience are ethically sensitive.

\section{References}

Atkinson, M. (2012). The empirical strikes back: doing realist ethnography. In K. Young and M. Atkinson (Ed.), Qualitative research on sport and physical culture (pp.23-50). Bingley, UK. Emerald Group Publishing.

Baron-Cohen, S. Tager-Flusberg, H. and Cohen, J. (2013). Understanding other minds: Perspectives from developmental cognitive neuroscience ( $3^{\text {rd }}$ Ed.). Oxford, Oxford University Press.

Black, K. and Stevenson, P. (2011). The inclusion spectrum [Retrieved from http://www.sportdevelopment.org.uk/index.php/home/98-disability-sport-a-physicalactivity/748-the-inclusion-spectrum?format=pdf[ (Accessed December 2018).

Blakeslee, S. and Blakeslee, M. (2007). The body has a mind of its own: how body maps in your brain help you do (almost) everything better. New York, NY: Random House. 
Bowman, W. (2004). Cognition and the body: Perspective from music education. In L. Bresler (Ed.), Knowing bodies, moving minds: Towards embodied teaching and learning (pp. 29-50). Dordecht, Netherlands: Kluwer.

Braun, V., Clarke, V. and Weate, P. (2016). Using thematic analysis in sport and exercise research. In B. Smith and A. Sparkes (Ed.), Routledge handbook of qualitative research in sport and exercise (pp. 191-205). London: Routledge.

British Educational Research Association (BERA) (2018) Ethical guidelines for educational research ( $2^{\text {nd }}$ Ed.). London: British Educational Research Association.

Bryman, A. (2015) Social research methods ( $5^{\text {th }}$ Ed.). Oxford: Oxford University Press.

Caldeborg, A., Maivorsdotter, N. and Öhman, M. (2019). Touching the didactic contract—a student perspective on intergenerational touch in PE. Sport, Education and Society, 24(3), 256-268.

Carrington, L., Kervin, L. and Ferry, B. (2011). Enhancing the development of pre-service teacher professional identity via an online classroom simulation. Journal of Technology and Teacher Education, 19, 351-368. 
Coates, J. (2012). Teaching inclusively: Are secondary physical education teachers sufficiently prepared to teach in inclusive environments?, Physical Education and Sport Pedagogy, 17(4), 349-365.

Cooper, B. (2011) Empathy in education: engagement, values and achievement. London: Continuum International Publishing Group.

Coplan, A. (2011). Understanding empathy: Its features and effects. In A. Coplan and P. Goldie (Ed.), Empathy: Philosophical and psychological perspectives (pp. 3-18). Oxford, Oxford University Press).

Creswell, J. and Poth, C. (2018). Qualitative inquiry and research design: choosing among five approaches (3rd ed.). London: Sage).

Denzin, N. and Lincoln, Y. (2011). Introduction: The discipline and practice of qualitative research. In N. Denzin and Y. Lincoln (Ed.), The sage handbook of qualitative research (pp. 1-19). London: Sage.

Dixon, M. and Senior, K. (2011). Appearing pedagogy: From embodied learning and teaching to embodied pedagogy, Pedagogy, Culture \& Society, 19, 473-484. 
Forgasz, R. and McDonough, S. (2017). "Struck by the way our bodies conveyed so much": A collaborative self-study of our developing understanding of embodied pedagogies, Studying Teacher Education, 13(1), 52-67.

Goodley, D. (2017). Disability studies: An interdisciplinary introduction (2 $2^{\text {nd }}$ Ed.). London: Sage.

Haegele, J. and Porretta, D. (2015). Physical activity and school-age individuals with visual impairments: A literature review, Adapted Physical Activity Quarterly, 32(1), 68-82.

Haegele, J. and Kirk, T. (2018). Experiences in physical education: Exploring the intersection of visual impairment and maleness. Adapted Physical Activity Quarterly, 35(2), 196-213.

Haegele, J. and Sutherland, S. (2015) Perspective of children with disabilities towards physical education: a qualitative inquiry review, Quest, 67(3), 255-273.

Haegele, J., Yessick, A. and Zhu, X. (2018). Females with visual impairments in physical education: Exploring the intersection of disability and gender identities. Research Quarterly for Exercise \& Sport, 89(3), 298-308. 
Haegele, J. and Zhu, X. (2017). Experiences of individuals with visual impairments in integrated physical education: A retrospective study. Research Quarterly for Exercise and Sport, 88(4), 425-435.

Haegele, J., Zhu, X. and Davis, S. (2017). The meaning of physical education and sport among elite athletes with visual impairments, European Physical Education Review, 23(4), 375-391.

Kurkova, P., Nemcek, D. and Labudova, J. (2015) Pupils with sensory disabilities in physical education classes. Acta Gymnastica, 45(3),139-145.

Lahman, M., Geist, M., Rodriguez, K., Graglia, P. and DeRoche, K. (2011). Culturally responsive relational reflexive ethics in research: The three Rs, Quality and Quantity, 45, $1397-1414$

Lieberman, L., Robinson, B. and Rollheiser, H. (2006) Youth with visual impairments: experiences in general physical education. RE:view, 38(1), 35-48.

Lieberman, L., Haegele, J., Columna, L. and Conroy, P. (2014). How students with visual impairments can learn components of the expanded core curriculum through physical education, Journal of Visual Impairment \& Blindness, 108(3), 239-248. 
Lieberman, L., Ponchillia, P. and Ponchillia, S. (2012). Physical education and sports for children with visual impairments and deafblindness: Foundations of instruction. USA: AFB Press.

Macintyre-Latta, M. and Buck, G. (2008). Enfleshing embodiment: "Falling into trust" with the body's role in teaching and learning, Educational Philosophy and Theory, 40(2), 315-329.

MacLachlan, M. (2004). Embodiment: clinical, critical and cultural perspectives on health and illness. Berkshire: Open University Press, McGraw-Hill.

Maher, A. (2018). "Disable them all": SENCO and LSA conceptualisations of inclusion in physical education, Sport, Education and Society, 23(2), 149-161.

Maher, A., Morley, D., Fimusanmi, J. and Ogilvie, P. (2017). University student experiences of a special school physical education placement. European Physical Education Review. Advanced online publication. [Retrieved from https://journals.sagepub.com/doi/10.1177/1356336X17746949].

van Manen, M. (1991). The tact of teaching: The meaning of pedagogical thoughtfulness. Albany: University of New York Press.

Maxwell, J. (2012). A realist approach for qualitative inquiry. London: Sage. 
Morley, D., Bailey, R., Tan, J. and Cooke, B. (2005). Inclusive physical education: teachers' views of including pupils with special educational needs and/or disabilities in physical education, European Physical Education Review, 11(1), 84-107.

Munro, M. (2018). Principles for embodied learning approaches, South African Theatre Journal, 31(1), 5-14.

Pivik, J., McComas, J., Macfarlane, I. and Laflamme, M. (2002). Using virtual reality to teach disability awareness, Journal of Educational Computing Research, 26(2), 203-218.

Salend, S. (2005). Using technology to teach about individual differences related to disabilities, Teaching Exceptional Children, 38(2), 32-38.

Singer, T. (2006). The neuronal basis and ontogeny of empathy and mind reading: review of literature and implications for future research, Neuroscience and Biobehavioral Reviews, $30(6), 855-863$.

Smith, B. and McGannon, K. (2018) Developing rigor in qualitative research: problems and opportunities within sport and exercise psychology, International Review of Sport and Exercise Psychology, 11(1), 101-121. 
Sparkes, A., Martos-Garcia, D. and Maher, A. (2017). Me, Imperfect Osteogenesis and my classmates in physical education lessons: A case study of embodied pedagogy in action, Sport, Education and Society. Advance online publication. [Retrieved from https://www.tandfonline.com/doi/full/10.1080/13573322.2017.1392939].

Sparkes, A. and Smith, B. (2014) Qualitative research methods in sport, exercise and health. London: Routledge.

Tant, M. and Watelain, E. (2016). Forty years later, a systematic literature review on inclusion in physical education (1975-2015): A teacher perspective, Educational Research Review, 19, 1-17.

Vickerman, P. and Coates, J. (2009). Trainee and recently qualified physical education teachers' perspectives on including children with special educational needs, Physical Education and Sport Pedagogy, 14(2), 137-153.

Vickerman, P. and Maher, A. (2018). Teaching physical education to children with special educational needs and disabilities ( $2^{\text {nd }}$ Ed.). London: Routledge. 